\title{
THE ROLE OF MOFS IN OUTCOME IN PATIENTS WITH SEPTIC SHOCK
}

\author{
Vikas Garg1, Anju Bhagtana², Jyoti Garg33, P. S. Nain ${ }^{4}$ \\ 1Associate Professor, Department of General Medicine, DMC and H, Ludhiana. \\ ${ }^{2}$ Senior Resident, Department of General Surgery, DMC and H, Ludhiana. \\ ${ }_{3}^{3}$ Senior Resident, Department of General Medicine, DMC and H, Ludhiana. \\ 4 Professor, Department of General Surgery, DMC and H, Ludhiana.
}

\section{BACKGROUND}

ABSTRACT

Multiple organ failure (MOF) is the main cause of death in ICUs, especially affecting septic patients. Infections are the primary outcome determinant of the MOFS in patients with septic shock. This is a prospective study conducted in DMC and H over a period of 15 months, where patients admitted to all kinds of Medicine Department ICU's were studied.

The objective of this study is to provide data from our college to study the incidence of MOFS in septic shock patients, number of organs involvement and its influence on mortality.

\section{MATERIALS AND METHODS}

A total of 104 patients were enrolled in the study. Patients were enrolled as per inclusion criteria for septic shock. Out of total 104 patients, 64 patients $(61.54 \%)$ had MOFS and 40 patients $(38.46 \%)$ were without MOFS. Out of 64 patients with MOFS, 18 patients had single organ involvement with mortality rate of $11.11 \%, 12$ patients had $2-3$ organs involvement, mortality rate of $33.33 \%$ and 34 patients were having more than 3 organs involvement with highest mortality rate of $70.58 \%$. UTI was found to be a major source of infection in $60.58 \%$ of patients.

\section{RESULTS}

The baseline demographic characteristics and various parameters of recovery of patients were evaluated and noted. Maximum number of patients, 29 (27.88\%) were in the age group of 56 - 65 years followed by age group 46 - 55 years $(22.12 \%)$.

\section{CONCLUSION}

So we conclude that MOF due to sepsis in an ICU is frequent with high mortality related to the number of failing organs, age and high APACHE II.

\section{KEYWORDS}

Multiple, Organ, Failure, Shock, Septic.

HOW TO CITE THIS ARTICLE: Garg V, Bhagtana A, Garg J, et al. The role of MOFS in outcome in patients with septic shock. J. Evolution Med. Dent. Sci. 2018;7(06):729-732, DOI: 10.14260/jemds/2018/165

\section{BACKGROUND \\ Severe sepsis and septic shock are leading causes of death in non-coronary ICUs in developed countries (Martin et al 2003,[1] Sands et al 1997).[2] Severe sepsis or septic shock accounts for as many deaths as acute myocardial infarction in hospitals (Angus et al, 2001).[3] The first clinical signs of sepsis include the unspecific symptoms of systemic inflammatory response (SIRS); fever, tachycardia, tachypnoea or elevation of the peripheral leukocyte count. Septic shock is \\ Although, supportive assistance to critically ill patients has improved a great deal, the mortality rates have remained the same in the last 2 decades.[7,9] These rates are directly related to factors such as number of organs affected [7,10] and the different sources of involved systems. ${ }^{[5,8]}$ So our aim is to conduct the study in our hospital to study the data related to the incidence of MOFS in septic shock patients, number of organs involvement and its influence on mortality. Sources of infections were also studied.} characterised by haemodynamic disturbances that need correction with vasopressor treatment. Treatment must promptly control the source of infection and restore haemodynamic homeostasis. Multiple Organ Failure (MOF) is considered the resulting process.[4] MOF can be due to an overwhelming inflammatory response secondary to trauma, ischaemia or unclear systemic inflammation.[5] MOF is the main cause of death in Intensive Care Units (ICU), especially affecting septic patients.[6,7,5,8]

'Financial or Other Competing Interest': None.

Submission 26-12-2017, Peer Review 20-01-2018,

Acceptance 27-01-2018, Published 05-02-2018.

Corresponding Author:

Dr. Anju Bhagtana,

\#101, PG Hostel, DMC\&H,

Ludhiana.

E-mail: anju_bhagtana@rediffmail.com

DOI: $10.14260 /$ jemds $/ 2018 / 165$

\section{MATERIALS AND METHODS}

A prospective observational study was conducted over a period of 15 months in Dayanand Medical College and Hospital, where patients were admitted to all kinds of Medicine Department ICU's of Dayanand Medical College and Hospital were studied. The duration of the study was from 01 ${ }^{\text {st }}$ Jan 2013 to $30^{\text {th }}$ March 2014. Total number of patients included in the study is 104 .

\section{Inclusion Criteria}

1. Within 24 hrs. of diagnosis of septic shock as evidenced by.

A. A systemic inflammatory response syndrome as defined by. 
Patients Matching Two or More of the following Criteria:

1. Fever (oral temperature $>38^{\circ} \mathrm{C}$ ) or hypothermia $\left(<36^{\circ} \mathrm{C}\right)$;

2. Tachypnoea ( $>24$ breaths $/ \mathrm{min})$;

3. Tachycardia (heart rate $>90$ beats $/ \mathrm{min}$ );

4. Leukocytosis $(>12,000 / \mathrm{uL})$, leucopenia $(<4,000 / \mathrm{uL})$ or $>10 \%$ bands.

B. Evidence for nidus of infection (proven or suspected infectious aetiology).

C. Arterial blood pressure $<90 \mathrm{mmHg}$ systolic or $40 \mathrm{mmHg}$, less than patient's normal blood pressure after fluid resuscitation for at least for 1 hour or need for vasopressors to maintain systolic blood pressure $>90$ mmHg.

\section{Exclusion Criteria}

1. Age $<18$ years.

2. Patients on exogenous steroids for more than 3 weeks.

3. Patients on chemotherapeutic agents.

4. Immune compromised patients- Malignancy, HIV, Rheumatological diseases.

5. Organ transplant recipients.

6. Patients who refuse to participate in the study.

7. Pregnant patient.

Statistical analysis was done using software SPSS 17.0. Statistical method for study included chi-square.

\section{RESULTS}

The baseline demographic characteristics and various parameters of recovery of patients were evaluated and noted. Maximum number of patients, 29 (27.88\%) were in the age group of 56 - 65 years followed by age group 46 - 55 years $(22.12 \%)$.

It has been observed that out of 104 patients, $57.69 \%$ were males and $42.31 \%$ were females (Figure 1 ).

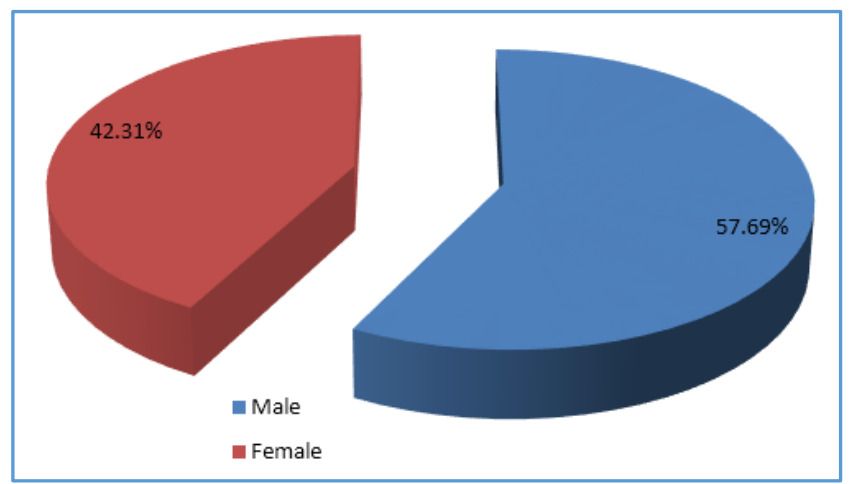

Figure 1. Sex Distribution

The expired rate was $36.67 \%$ among males as compared to $29.54 \%$ in females.

In our study, in total 104 patients there were total 129 sources of infection identified with some patients having multiple sources of infection. Urinary tract was the major source of infection in 63 patients $(60.58 \%)$.

Out of the total 104 patients, $64(61.54 \%)$ patients were having multiorgan failure. 40 patients [38.46\%)] did not have multiorgan involvement (Figure 2).
Out of the total 64 patients with MOFS, 20 (31.24\%) recovered, 14 (21.88\%) were DAMA and 30 (46.88\%) patients expired. Out of the total 40 patients without MOFS, $25(62.50 \%)$ recovered, $10(25 \%)$ were DAMA and 5 (12.50\%) patients expired. P-value for Expired patients in two groups is 0.007 , which is statistically significant.

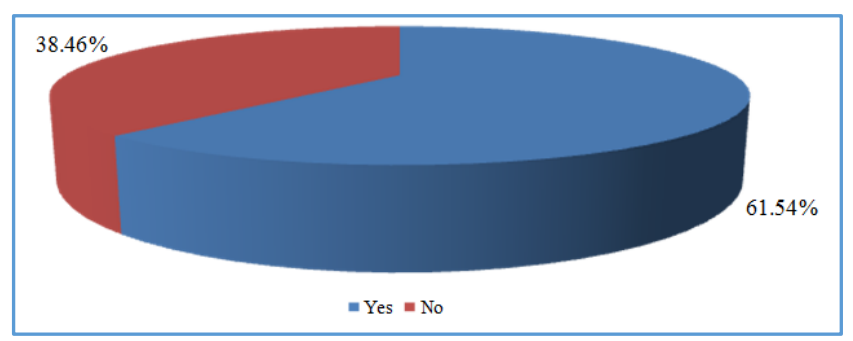

Figure 2. Distribution of Subjects according to MOFS ( $n=104)$

Out of 64 patients with MOFS 18 patients had single organ involvement, out of which 15 patients recovered, 1 was DAMA and 2 expired with a mortality rate of $11.11 \% .12$ patients had 2 - 3 organs involvement, out of which 5 patients recovered and 4 expired (33.33\%). 34 patients were having more than 3 organs involvement. None of these patients recovered. 24 patients expired (70.58\%) (Figure 3).

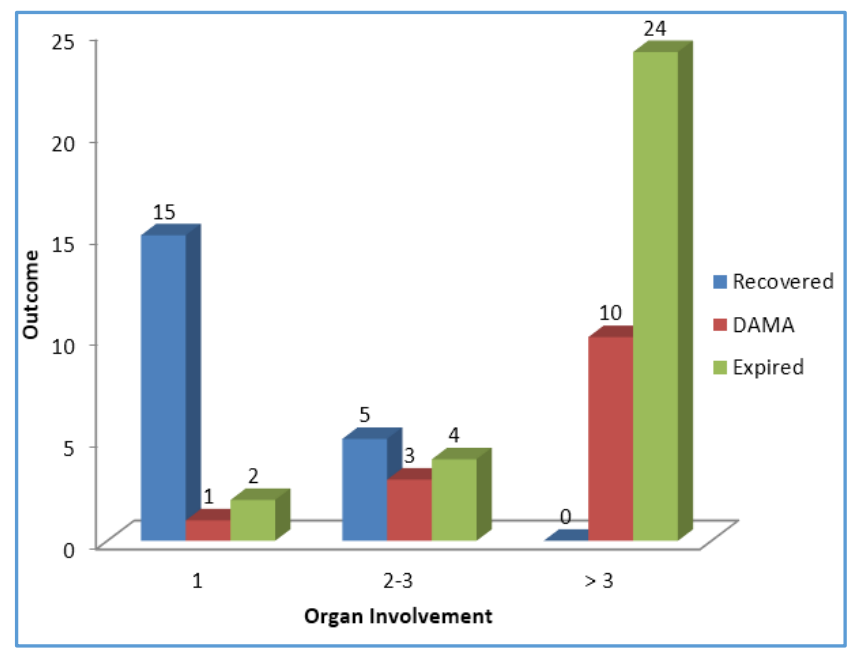

Figure 3. Outcome in Relation to Organ Involvement in Patients with MOFS $(n=64)$

Mean APACHE score in recovered patients at 0, 24 and 48 hours was $27.13 \pm 5.61,22.78 \pm 5.83$ and $19.40 \pm 5.28$ respectively with a p-value of 0.007 ( $0 \mathrm{hr}$. vs. $24 \mathrm{hrs}$.), 0.001 ( 0 hr. vs. 48 hrs.) and 0.009 (24 hrs. vs. 48 hrs.) which is statistically significant.

Mean APACHE score in expired patients at 0, 24 and 48 hours was $30.37 \pm 5.51,33.69 \pm 6.04$ and $37.00 \pm 5.35$ respectively with a p-value of 0.041 ( $0 \mathrm{hr}$. vs. $24 \mathrm{hrs}$.), 0.005 ( 0 hr. vs. 48 hrs.) and 0.040 (24 hrs. vs. 48 hrs.) which is statistically significant.

\section{DISCUSSION}

Severe sepsis and septic shock are leading causes of death in non-coronary ICUs in developed countries (Martin et al 2003,[1] Sands et al 1997).[2] Severe sepsis or septic shock accounts for as many deaths as acute myocardial infarction in hospitals (Angus et al 2001).[3] The first clinical 
signs of sepsis include the unspecific symptoms of systemic inflammatory response (SIRS); fever, tachycardia, tachypnoea or elevation of the peripheral leukocyte count.

Sepsis and septic shock continues to be major cause of morbidity and mortality. It is the tenth most common cause of death in united states. Although, support for critically ill patients has significantly improved during the past 50 years, and knowledge about pathophysiology of conditions such as shock, acute renal failure and acute respiratory failure has also improved, patients have longer survival, but mortality remains high. Patients started dying due to complications of their diseases, rather than the diseases themselves.[9,11] For the first time, physicians faced an overwhelming inflammatory response, leading to a progressive deterioration of patients' organ function with mortality rates up to $50 \% .[4,11]$

Actually, MOF became the main cause of death in ICUs and since the first studies which described this entity during the 1970s, mortality remains almost the same, in spite of all the research in laboratories and ICUs. $[4,5,10,9]$ The mortality of ICU septic patients ranges from $20 \%$ to $60 \% \cdot{ }^{[5,10,11,12]}$ Poole, et al[9] observed a $66 \%$ mortality, while in our study it was $46.88 \%$.

In the present study, patients having single major organ involvement showed a mortality rate of $11.11 \%$ (out of total 64 patients with MOFS). Patients with 2 - 3 major organ involvement had a mortality rate of $33.33 \%$ and those with more than 3 organs involvement had $70.58 \%$ mortality indicating poor prognosis in patients with MOFS.

This is in comparison to the study conducted by Elizabeth $B$ et al[13] in 2001 in patients with MOFS in septic shock showing a mortality of $18 \%$ in single organ involvement, $52 \%$ in 2 - 3 organs involvement and $88 \%$ in more than 4 organs involvement.

The above studies correlate well with our study indicating a higher mortality rate in patients with MOFS. All patients included in the study were in the age group from 18 85 years. Maximum number of patients, 29 (27.88\%) were in the age group of 56 - 65 years followed by age group $46-55$ years $(22.12 \%)$. The age distribution is comparable to the previous study done by Briegel J et al.[14]

Age thus plays a major role in mortality due to septicaemia. Out of the total 104 patients, 60 patients (57.69\%) were males and 44 patients (42.31\%) were females. In male patients out of 60 patients 24 recovered (40\%), 22 expired (36.66\%) and 14 were DAMA (23.33\%). In females out of total 44 patients, 21 recovered (47.72\%), 13 expired (29.54\%) and 10 were DAMA (27.72\%). So in our study it has been observed that male patients have higher mortality as compared to female patients.

In our study in total 104 patients, there were total 129 sources of infection. Urinary tract was the major source of infection in 63 patients $(60.58 \%)$ followed by respiratory tract in 43 patients ( $41.35 \%$ of total infection sources).

In $11(10.57 \%)$ patients, GIT was the source. Soft tissue was identified as the source of infection in 10 (9.62\%) of patients. 1 patient $(0.96 \%)$ each had CNS and CRBSI as source of infection.

This is comparable to the previous studies by various authors, which concluded that the lung is the primary source of infection both in severe sepsis and in septic shock followed by the abdomen, the urinary tract, soft tissues and primary blood stream infection (Annane et al, 2003).[15]

Deepak CL et al[16] in their study concluded that mean Apache II score in patients who died was 24.2 compared to the patients who recovered was 18.5 (p .002). They observed Apache II score of $>21$ have sensitivity of $76 \%$ and specificity of $60 \%$ in predicting mortality in patients with sepsis, which was statistically significant (p.010).

In the present study, Apache II score at 0 hour was 28.65, at 24 hours - 27.16 and at 48 hours was 26.00 showing the declining trend with a p-value of 0 vs. $24 \mathrm{hrs}$. -0.03 and 0 vs. 48 hrs. - 0.018 that is statistically significant.

Also mean Apache II score in recovered patients was $24 \pm 3$ SD and in expired patients was $29 \pm 2$ SD.

\section{CONCLUSION}

So we observed a correlation between mortality and number of systems with failure as well as between mortality and age. There was significant difference in Apache II values between survivors and non-survivors.

\section{REFERENCES}

[1] Martin GS, Mannino DM, Eaton S, et al. The epidemiology of sepsis in the United States from 1979 through 2000. N Engl J Med 2003;348(16):1546-54.

[2] Sands KE, Bates DW, Lanken PN, et al. Epidemiology of sepsis syndrome in 8 academic medical centers. JAMA 1997;278(3):234-40.

[3] Angus DC, Linde-Zwirble WT, Lidicker J, et al. Epidemiology of severe sepsis in the United States: analysis of incidence, outcome and associated costs of care. Crit Care Med 2001;29(7):1303-10.

[4] Zimmerman JE, Knaus WA, Sun X, et al. Severity stratification and outcome prediction for multisystem organ failure and dysfunction. World J Surg 1996;20(4):401-5.

[5] Bosscha K, Reijnders K, Hulstaert PF, et al. Prognostic scoring system to predict outcome in peritonitis and intra-abdominal sepsis. Br J Surg 1997;84(11):1532-4.

[6] Nathens AB, Marshall JC. Sepsis, SIRS and MODS: What's in a name? World J Surg 1996;20(4):386-91.

[7] Hebert PC, Drummond AJ, Singer J, et al. A simple multiple system organ failure scoring system predicts mortality of patients who have sepsis syndrome. Chest 1993;104(1):230-5.

[8] Bone RC, Balk RA, Cerra FB, et al. Definitions for sepsis and organ failure and guidelines for the use of innovative therapies in sepsis. American College of Chest Physicians/Society of Critical Care Medicine consensus conference commitee. Chest 1992;101(6):1644-55.

[9] Poole GV, Muakkassa FF, Griswold JA. The role of infection in outcome of multiple organ failure. Am Surg 1993;59(11):727-32.

[10] Goris RJA, te Boekhorst TPA, Nuytinck JKS, et al. Multiple organ failure. Generalized autodestructive inflamation? Arch Surg 1985;120(10):1109-15.

[11] Beal AL, Cerra FB. Multiple organ failure syndrome in the 1990s. Systemic inflammatory response and organ dysfunction. JAMA 1994;271(3):226-33. 
[12] Fourrier F, Chopin C, Goudemand J, et al. Septic shock, multiple organ failure and disseminated intravascular coagulation. Compared patterns of antithrombin III, protein $\mathrm{C}$ and protein $\mathrm{S}$ deficiencies. Chest 1992;101(3):816-23.

[13] Bilevicius E, Dragosavac D, Dragosavac S, et al. Multiple organ failure in septic patients. The Brazilian Journal of Infectious Diseases 2001;5(3):103-10.

[14] Briegel J, Forst H, Haller M, et al. Stress doses of hydrocortisone reverse hyperdynamic septic shock: a prospective, randomized, double-blind, single-center study. Crit Care Med 1999;27(4):723-32.
[15] Annane D, Bellissant E, Bollaert PE, et al. Corticosteroids in the treatment of severe sepsis and septic shock in adults: a systematic review. JAMA 2009;301(22):2362-75.

[16] Deepak CL, Smitha B. Prediction of outcome in patients with sepsis using $C$ - reactive protein \& APACHE II scoring system. IOSR Journal of Dental and Medical Sciences (IOSR-JDMS) 2014;13(3),Ver.V:17-20. 